\title{
Epidermal growth factor (EGF)-receptor signalling is needed for murine beta cell mass expansion in response to high-fat diet and pregnancy but not after pancreatic duct ligation
}

\author{
E. Hakonen • J. Ustinov • I. Mathijs • J. Palgi • \\ L. Bouwens • P. J. Miettinen • T. Otonkoski
}

Received: 21 December 2010 /Accepted: 21 March 2011 /Published online: 21 April 2011

(C) Springer-Verlag 2011

\begin{abstract}
Aims/hypothesis Epidermal growth factor receptor (EGFR) signalling is essential for the proper fetal development of pancreatic islets and in the postnatal formation of an adequate beta cell mass. In this study we investigated the role of EGFR signalling in the physiological states of beta cell mass expansion in adults during metabolic syndrome and pregnancy, as well as in regeneration after pancreatic duct ligation.

Methods Heterozygous Pdxl-EGFR-dominant-negative (E1-DN) mice, which have a kinase-negative EGFR under the $P d x 1$ promoter, and wild-type mice were both subjected to a high-fat diet, pregnancy and pancreatic duct ligation. Results The beta cell mass of wild-type mice fed the highfat diet increased by $70 \%$ and the mice remained
\end{abstract}

P. J. Miettinen and T. Otonkoski contributed equally to this study.

Electronic supplementary material The online version of this article (doi:10.1007/s00125-011-2153-1) contains supplementary material,

which is available to authorised users.

E. Hakonen $(\bowtie) \cdot J$. Ustinov $\cdot$ J. Palgi $\cdot$ P. J. Miettinen •

T. Otonkoski

Research Programs Unit, Molecular Neurology,

Biomedicum Stem Cell Centre, University of Helsinki,

PO Box 63, (Haartmaninkatu 8),

00014 Helsinki, Finland

e-mail: elina.hakonen@helsinki.fi

P. J. Miettinen - T. Otonkoski

Hospital for Children and Adolescents,

University of Helsinki and Helsinki University Central Hospital,

Helsinki, Finland

I. Mathijs $\cdot$ L. Bouwens

Cell Differentiation Laboratory, Vrije Universiteit,

Brussels, Belgium normoglycaemic; the E1-DN mice became diabetic and failed to show any compensatory beta cell mass expansion. Similarly, pregnant wild-type mice had four times more proliferating beta cells and a $75 \%$ increase in beta cell mass at mid-gestation, in contrast to the pregnant E1-DN mice, which did not show any significant beta cell compensation and were hyperglycaemic in an intraperitoneal glucose tolerance test. However, after pancreatic duct ligation, both the wild-type and E1-DN mice showed similar expression of Ngn3 (also known as Neurog3) and beta cell proliferation increased to a similar level in the ligated part of pancreas. Conclusions/interpretations EGFR signalling is essential in beta cell mass expansion during a high-fat diet and pregnancy where replication is the primary mechanism for compensatory beta cell mass expansion. In contrast, EGFR signalling appears not to be crucial to increased beta cell proliferation after pancreatic duct ligation.

Keywords Beta cell mass - EGFR - High-fat diet .

Pancreatic duct ligation · Pregnancy

\begin{tabular}{|c|c|}
\hline \multicolumn{2}{|c|}{ Abbreviations } \\
\hline E1-DN & $P d x 1$-EGFR-dominant-negative \\
\hline EGF & Epidermal growth factor \\
\hline (h)EGFR & (Human) Epidermal growth factor receptor \\
\hline GD & Gestational day \\
\hline GLP-1 & Glucagon-like peptide 1 \\
\hline 5-HTR2B & 5-Hydroxytryptamine receptor- $2 \mathrm{~b}$ \\
\hline IPGTT & Intraperitoneal glucose tolerance test \\
\hline Ki67 & $\begin{array}{l}\text { Antigen identified by monoclonal } \\
\text { antibody Ki67 }\end{array}$ \\
\hline MAPK & Mitogen-activated protein kinase \\
\hline NGN3 & Neurogenin 3 \\
\hline PI3 & Phosphatidyl inositol-3 \\
\hline
\end{tabular}




\section{Introduction}

The achievement and maintenance of an adequate and functional beta cell mass is important for glucose homeostasis and is controlled at all stages of development. In rodents the beta cell mass is mostly determined during the last days of gestation and first postnatal weeks $[1,2]$. In adulthood the beta cell mass remains quite constant under normal physiological circumstances, with very low rates of beta cell replication [3, 4]. However, beta cells adaptively compensate for both physiological and pathophysiological states of insulin resistance, including pregnancy and metabolic syndrome [5-10]. During metabolic syndrome and the associated insulin resistance, the normal pancreatic beta cell response is compensatory insulin hypersecretion in order to maintain normoglycaemia. This compensation involves the expansion of the beta cell mass and enhanced insulin synthesis and secretion [5, 8-12]. The same is probably true in obese non-diabetic humans, although the increase in beta cell mass (about 50\%) is less than that seen in mice [13]. Also, during pregnancy the maternal pancreatic beta cell mass increases both in rodents and humans to meet the increased physiological demands $[6,14,15]$. There is plenty of evidence for replication being the primary mechanism for beta cell mass expansion during obesity-induced insulin resistance and pregnancy in mice [7, 9, 16-18].

Another well-characterised situation of rapid beta cell mass expansion is pancreatic regeneration that occurs after partial pancreatectomy and in pancreatic inflammation triggered by ligation of the pancreatic duct [19-22]. The beta cell mass doubles in 1 week in the ligated part of the pancreas, which cannot be explained by replication alone without additional sources of new beta cells [19, 23]. Neurogenin 3 (NGN3)-positive precursor cells have indeed been shown to recapitulate the embryonic programme of islet differentiation in the duct-ligated pancreas [23]. The origin of the Ngn3-expressing endocrine precursor cells remains unclear, however. One possibility for beta cell regeneration is direct conversion of glucagon-producing alpha cells into beta cells, which has been demonstrated in a model of extreme rapid beta cell loss [24].

Epidermal growth factor receptor (EGFR) is a tyrosine kinase receptor [25] belonging to the ERBB receptor family, consisting of EGFR/ERBB1, NEU/ERBB2, ERBB3 and ERBB4 [26, 27]. All ERBBs are produced in the developing pancreas $[28,29]$. We have previously shown that the EGFR is essential for normal pancreatic development and important in postnatal beta cell growth. In EGFRdeficient mice the development of beta cells occurs at a later stage and the nascent beta cells have a migration defect [30]. We further showed that ligands of the EGFR/ ERBB1 and ERBB4 receptors, particularly betacellulin, regulate the lineage determination of developing islet cells [29]. In mice expressing a dominant-negative EGFR under the $P d x l$ promoter (E1-DN mice), the relative beta cell surface area is markedly reduced because of impaired beta cell proliferation [31]. In the E1-DN beta cells the phosphorylation of EGFR and the activation of downstream-signalling molecules is downregulated by approximately $40 \%$ in homozygous animals. The phenotype of heterozygous E1-DN mice, which were used in these experiments, is less pronounced, and the heterozygous mice are nearly normoglycaemic under normal circumstances [31].

This study aims to elucidate the role of EGFR-mediated signalling in the expansion of beta cells during metabolic challenges or pancreatic regeneration. The E1-DN mice were challenged with high-fat diet or pregnancy, two conditions known to be associated with increased beta cell replication. Finally, the same mice were subjected to pancreatic duct ligation, a model for islet neogenesis.

\section{Materials and methods}

Animals and experimental setup FVB E1-DN mice were generated as previously described by Miettinen et al. [31]. Briefly, the E1-DN transgene consists of the mouse $P d x 1$ promoter, followed by a rabbit $\beta$-globin second intron, the human kinase-deficient $E G F R$ cDNA with a myc tag and a growth hormone polyA tail [31]. The study protocol was approved by the Animal Ethics Committee of the University of Helsinki and the principles of laboratory animal care were followed. Wild-type controls were derived from litters or non-related litters.

For the high-fat diet experiment, 5-week-old heterozygous male mice (FVB Pdxl-EGFR-DN) were fed on a high-fat diet (TD 06414, Harlan Laboratories, Indianapolis, IN, USA) or standard chow (Altromin 1324; Altromin, Lage, Germany) for 8 weeks. Proliferating cells were continuously labelled by administering BrdU (Sigma-Aldrich, St Louis, MO, USA) in drinking water $(1 \mathrm{mg} / \mathrm{ml})$. An intraperitoneal glucose tolerance test (IPGTT) was performed after 4 and 8 weeks. The mice were killed immediately after the second IPGTT and the pancreases collected.

For the pregnancy experiment, 12-week-old heterozygous female mice (E1-DN FVB) were mated with male FVB mice. Mating was confirmed by the presence of a vaginal plug the next morning, designated as day 0.5 of gestation. An IPGTT was performed on day 13.5 and the mice were killed and the pancreases collected on day 14.5 of pregnancy.

For the pancreatic duct ligation the E1-DN and the wildtype mice were sent to Brussels and left to adapt to the new environment for 1 week prior to the operation. The 
pancreatic duct of 9 week old mice (E1-DN FVB) was ligated as described in rats by Wang et al. [19] with some minor modifications. The mice were killed 7 days after the operation and the pancreatic head and tail parts were collected separately.

IPGTT Glucose (10\% [wt/vol.] solution, $1 \mathrm{mg} / \mathrm{g}$ body weight) was injected i.p. Blood samples were collected at 0, 30, 60 and $120 \mathrm{~min}$ and glucose concentrations were measured from whole blood using a clinical glucose meter (OneTouch Ultra glucose meter; Lifescan, Milpitas, CA, USA).

Immunohistochemistry and beta cell mass analysis The mice were killed by $>70 \%$ carbon dioxide followed by cervical dislocation, and the pancreases were dissected, weighed and fixed overnight in $4 \%$ (wt $/$ vol. in phosphate buffer) paraformaldehyde following embedding in paraffin. The paraffin sections were stained as described previously by Huotari et al. [29]. In brief, the deparaffinised rehydrated sections were treated with $1 \mathrm{mmol} / \mathrm{l}$ EDTA buffer ( $\mathrm{pH} 8)$ in a microwave oven to reveal antigen sites. The sections were incubated for $10 \mathrm{~min}$ in Ultra V Block (Thermo Scientific, Waltham, MA, USA) to block non-specific binding sites prior to incubation overnight at $4{ }^{\circ} \mathrm{C}$ with a primary antibody (guinea pig anti-swine insulin [DakoCytomation, Glostrup, Denmark]; mouse anti-BrdU [DakoCytomation, Glostrup, Denmark]; rabbit anti-human antigen identified by monoclonal antibody Ki67 [Ki67; Novocastra, Newcastle upon Tyne, UK]; mouse anti-mouse neurogenin 3 [Beta Cell Biology Consortium, Nashville, TN, USA]; and rabbit anti-human cleaved caspase 3 [Cell Signaling Technology, Danvers, MA, USA]) diluted in PBS containing $0.1 \%$ Tween 20 (vol./vol.) (Sigma-Aldrich). For lightmicroscopy staining the sections were incubated for $30 \mathrm{~min}$ at room temperature with biotinylated secondary antibody (Zymed Laboratories, South San Francisco, CA, USA), rinsed and incubated with peroxidase-conjugated streptavidin (Zymed Laboratories). The sections were finally developed with 3-amino-9-ethyl-carbazole substrate (Thermo Scientific). For fluorescence microscopy, the following secondary antibodies were used: donkey antimouse IgG (Alexa, A21202, Invitrogen, Carlsbad, CA, USA); goat anti-guinea pig IgG (Alexa, A11076, Invitrogen); donkey anti-rabbit IgG (Alexa, A21206, Invitrogen). Nuclear staining was performed with DAPI (Vectashield with DAPI, Vector Laboratories, Burlingame, CA, USA).

For the beta cell mass analysis, the pancreases were sectioned and five sections, one per $50-100 \mu \mathrm{m}$, were analysed. These sections were stained for insulin, counterstained with haematoxylin and morphometrically analysed directly under light microscopy using an Image-Pro Analyzer 6.0 (Media Cybernetics, Bethesda, MD, USA).
The beta cell mass was calculated by multiplying the relative cross-sectional area of the insulin-positive area per total pancreatic tissue area by the weight of the pancreas.

RT-PCR Total RNA from E1-DN and wild-type mice pancreases was isolated 7 days after pancreatic duct ligation with TRIzol (Invitrogen) and RNA quality was controlled with 2100 Bioanalyzer (Agilent Technologies, Santa Clara, CA, USA). The PCR analysis for Ngn3 mRNA expression was made with the following primers: forward $5^{\prime}$ AAGAGCGAGTTGGCACTCAG-3' and reverse 5'TACAAGCTGTGGTCCGCTAT-3' (amplicon 227 bp, NM 009719.4 position 454-680) according to the following PCR protocol: denaturation for $2 \mathrm{~min}$ at $95^{\circ} \mathrm{C}$, followed by 36 cycles of $35 \mathrm{~s}$ at $95^{\circ} \mathrm{C}, 35 \mathrm{~s}$ at $59^{\circ} \mathrm{C}, 35 \mathrm{~s}$ at $72^{\circ} \mathrm{C}$, followed by a $7 \mathrm{~min}$ extension at $72^{\circ} \mathrm{C}$. Full-length mouse Ngn3 cDNA (gift from H. Edlund, Umeå University, Sweden) was used as a positive control.

DNA extraction and genotyping of the mice was done as previously described by Miettinen et al. [31].

Statistical analysis All data are expressed as the mean \pm SE. Mean and SE values are calculated from at least three experiments. Significance of the differences between two groups was measured by Student's unpaired $t$ test. Differences between more than two groups were calculated with one-way ANOVA followed by Tukey's test, using SPSS PASW Statistics 18 software. General linear model with repeated measurements was used to calculate significances between the IPGTT values, using the same software. $p<0.05$ was used as the limit for statistical significance.

\section{Results}

High-fat diet Wild-type and E1-DN mice were fed on either the high-fat diet or standard chow for 8 weeks. During this period the two genotypes showed similar significant weight gain on the high-fat diet (Fig. 1a). The transgene expression driven by the $P d x l$ promoter was similar with both diets, as shown by immunohistochemistry (electronic supplementary material [ESM] Fig. 1c-f). After 8 weeks the fasting blood glucose of E1-DN mice had increased from 9 to $16 \mathrm{mmol} / \mathrm{l}$ when fed with the highfat diet, while the wild-type mice maintained normal fasting blood glucose levels (Fig. 1b). In an IPGTT the glucose tolerance of obese wild-type mice was only slightly impaired, with a $2 \mathrm{~h}$ blood glucose average of $14 \mathrm{mmol} / \mathrm{l}$ compared with $10 \mathrm{mmol} / \mathrm{l}$ on standard chow. In contrast, the E1-DN mice fed the high-fat diet were overtly diabetic with blood glucose values over $25 \mathrm{mmol} / \mathrm{l}$ at $2 \mathrm{~h}$ after glucose injection (Fig. 1b). 

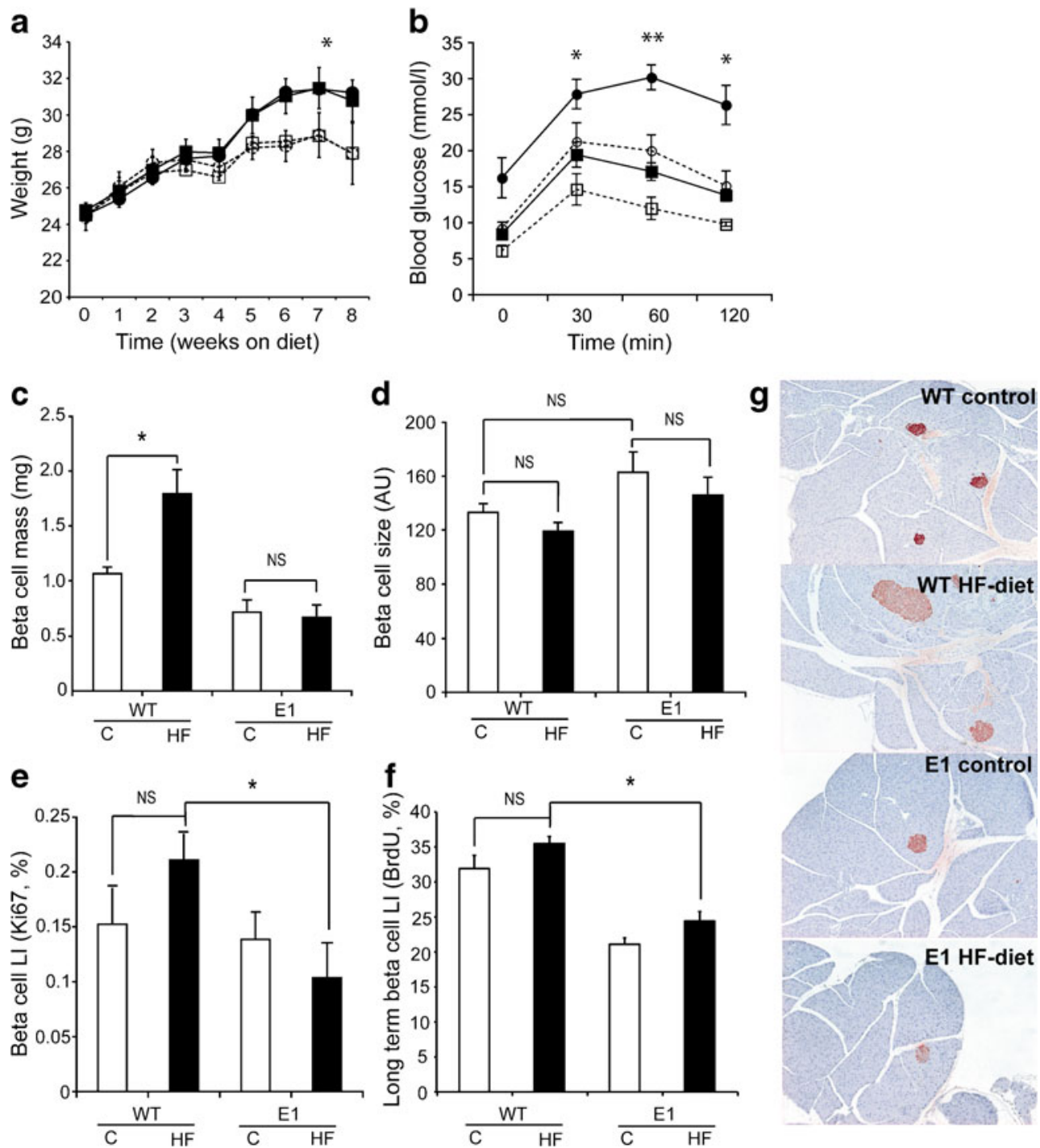

E1 control

Fig. 1 Development of diabetes and failure of beta cell mass expansion in the E1-DN mice during high-fat feeding. a Body weight of the E1-DN and wild-type mice during 8 weeks on a standard chow or high-fat diet $(n=6)$. b After 8 weeks on a standard chow or high-fat diet wild-type and E1-DN mice were intraperitoneally injected with glucose $(1 \mathrm{mg} / \mathrm{g}$ body weight) and blood glucose values were measured at the time intervals indicated $(n=6)$. Circles, E1-DN mice; squares, wild-type mice; black symbols, high-fat diet; white symbols, standard chow. c, d Quantification of the beta cell mass (c) and the mean beta cell size (d) in the wild-type and E1-DN mice after 8 weeks on a standard chow or high-fat diet $(n=6)$. e Replication rate of beta cells, expressed by insulin and Ki67 double-positive cells relative to insulin-positive cells $(n=6)$. f Beta cell proliferation analysis after 8 weeks of continuous BrdU labelling via drinking water $(n=3)$. Black bars, high-fat diet; white bars, standard chow. g Histological analysis of pancreatic islets of wild-type and E1-DN mice after 8 weeks on standard chow or high-fat diet. Sections were stained with anti-insulin antibody. Original magnification $\times 4$. Representative islets are shown. Values represent mean \pm SE. ${ }^{*} p<0.05,{ }^{* *} p<0.01$. C, control; HF, highfat; LI, labelling index; WT, wild-type
We analysed the beta cell mass after 1 and 8 weeks from the onset of the diet. At 1 week, the beta cell mass did not show any signs of compensation (data not shown). After 8 weeks, the high-fat diet resulted in a 1.7-fold increase in beta cell mass in the wild-type mice, but no increase was observed in the E1-DN mice (Fig. 1c,g). The individual beta cell size remained unaffected by the diet in both groups (Fig. 1d), suggesting that the beta cell mass increase was due to an increase in cell number rather than hypertrophy.
The increased number of beta cells in wild-type mice fed the high-fat diet could be caused by replication of preexisting beta cells, neogenesis (generation of new beta cells from non-beta cells), reduced apoptosis, or a combination of these mechanisms. To address this question, we analysed the rates of proliferation and apoptosis of the beta cells in these mice by Ki67 and caspase 3 immunohistochemistry and long-term BrdU incorporation. After the 8 week highfat diet, there was a trend for increased Ki67 labelling of 
insulin-immunoreactive cells in the wild-type mice, but this difference did not reach statistical significance $(0.15 \%$ vs $0.21 \%, p=0.12$ ). In contrast, the E1-DN mice showed a slight non-significant decrease in beta cell proliferation while on the high-fat diet $(0.13 \%$ on standard chow vs $0.10 \%$ on high-fat diet) (Fig. 1e). We also analysed the beta cell proliferation after 1 week on the diet but at this time point there were no differences between the diets in either group (data not shown). We further carried out long-term BrdU labelling by adding BrdU to the drinking water of the mice, which has been demonstrated to label all proliferating cells throughout the labelling period [4]. After 8 weeks of continuous BrdU administration, the proportion of insulin and BrdU double-positive cells was up to $30 \%$ even in the mice that had eaten standard chow. Surprisingly, we did not detect any significant increase in the proportion of BrdU and insulin double-positive cells after the 8 week high-fat diet (Fig. 1f). However, both BrdU labelling and Ki67 immunostaining showed that beta cell proliferation with the high-fat diet was significantly higher in the wild-type mice compared with the E1-DN mice (Fig. 1e-f).

Activated (i.e. cleaved) caspase 3 immunohistochemistry revealed no differences between the beta cell apoptosis rate after 1 and 8 weeks on the diet. Overall, only very rare apoptotic islet cells were identified (data not shown). We also looked for NGN3-immunoreactive cells as a possible sign of islet neogenesis, but did not detect any positive cells in any of the mice (data not shown).

Pregnancy We have previously shown that female E1-DN mice are less hyperglycaemic than males despite a similar beta cell mass defect [31]. In line with this, the glucose tolerance of non-pregnant female E1-DN mice did not differ from wild-type controls in the IPGTT (Fig. 2a). However, at gestational day (GD) 13.5 the pregnant E1DN mice displayed impaired glucose tolerance when compared with the pregnant wild-type mice (Fig. 2b). The transgene expression during pregnancy did not change (ESM Fig. 1c-d, g-h).

The beta cell mass of wild-type mice increased by $75 \%$ during pregnancy $(1.04 \mathrm{mg}$ in non-pregnant females vs $1.82 \mathrm{mg}$ in pregnant mice, $p<0.001)$. In striking contrast, the E1-DN mice did not show any significant adaptive increase in the beta cell mass $(0.47 \mathrm{mg}$ in control vs $0.57 \mathrm{mg}$ in pregnant mice, $p=0.95$ ) (Fig. 2c). Beta cell proliferation was again analysed by Ki67/insulin double labelling. The wild-type mice displayed a fourfold increase in beta cell proliferation at GD 14.5 compared with nonpregnant control mice, whereas the proliferation rate of the E1-DN mice did not increase significantly (Fig. 2d). There was no increase in the number of apoptotic beta cells at this stage of pregnancy in any of these groups, studied with activated caspase 3 immunostaining (data not shown).
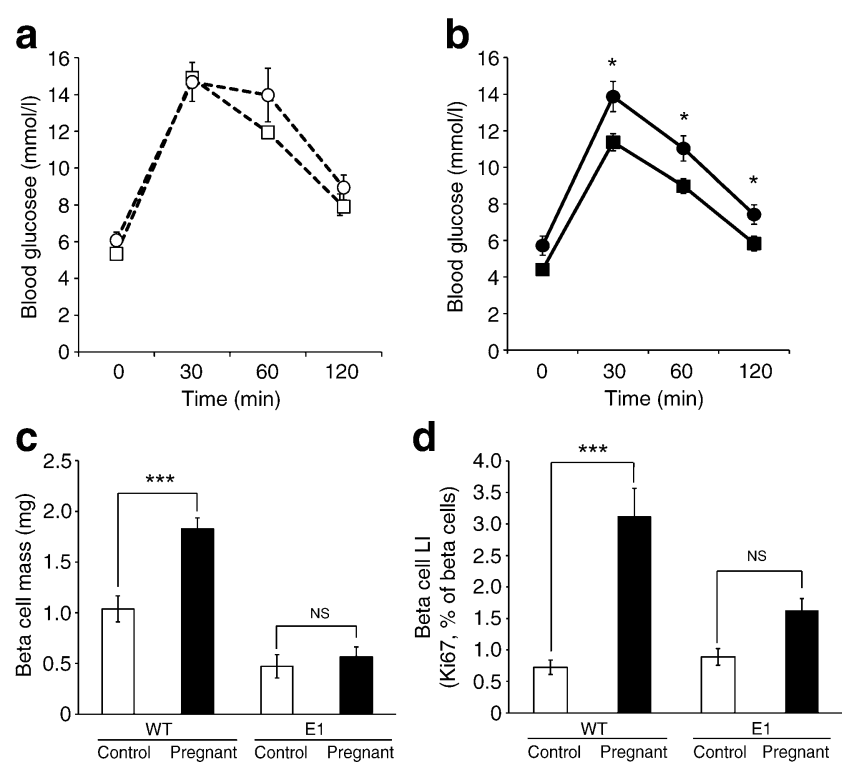

Fig. 2 Development of impaired glucose tolerance through defects in beta cell proliferation and beta cell mass compensation in the E1-DN mice during pregnancy. a, b Blood glucose concentrations, measured at the time intervals indicated after an i.p. injection of glucose $(1 \mathrm{mg} / \mathrm{g}$ body weight) in non-pregnant (a) and pregnant (13.5 GD) (b) wildtype (squares) and E1-DN (circles) mice $(n=5-7)$. c The beta cell mass of wild-type pregnant 14.5 GD mice is significantly higher than that of non-pregnant mice $(p<0.001)$. There is no difference between groups of E1-DN mice $(p=0.95)(n=5-7)$. d Beta cell proliferation (quantified by Ki67 and insulin double-positive cells relative to the total number of insulin-positive cells) is significantly higher during pregnancy in wild-type mice $(p<0.001)$, but not in E1-DN mice $(p=0.27)(n=5-7)$. White bars, non-pregnant; black bars, pregnant. Values represent mean \pm SE. ${ }^{*} p<0.05$, $* * * p<0.001$. LI, labelling index; WT, wild type

Pancreatic duct ligation Pancreatic duct ligation was performed in male wild-type and E1-DN mice at the age of 9 weeks. At 1 week after the operation most of the acinar cells had disappeared from the tail of the operated mice and many remaining acinar cells were positive for activated caspase 3 as a sign of apoptosis. The density of ductal structures had increased (Fig. 3c) and ductal cells were actively proliferating (data not shown). Transgene expression after pancreatic duct ligation was confirmed by immunohistochemistry (ESM Fig. 1i-j). Ngn3 mRNA expression was upregulated in the tail of the operated mice in both the wild-type and the E1-DN mice (Fig. 3e). The total insulin-positive surface area increased more than sixfold in the pancreatic tail of the wild-type mice 1 week following surgery (Fig. 3a,c). In the E1-DN mice, the total insulinpositive surface area was increased more than fourfold in the pancreatic tail compared with the pancreatic head (Fig. 3a,c).

Beta cell proliferation increased in the ligated tail part to a similar level (1.1\%) in both the wild-type and the E1-DN mice, analysed by Ki67 labelling of insulin-positive cells (Fig. 3b). Islet density also increased in both groups 

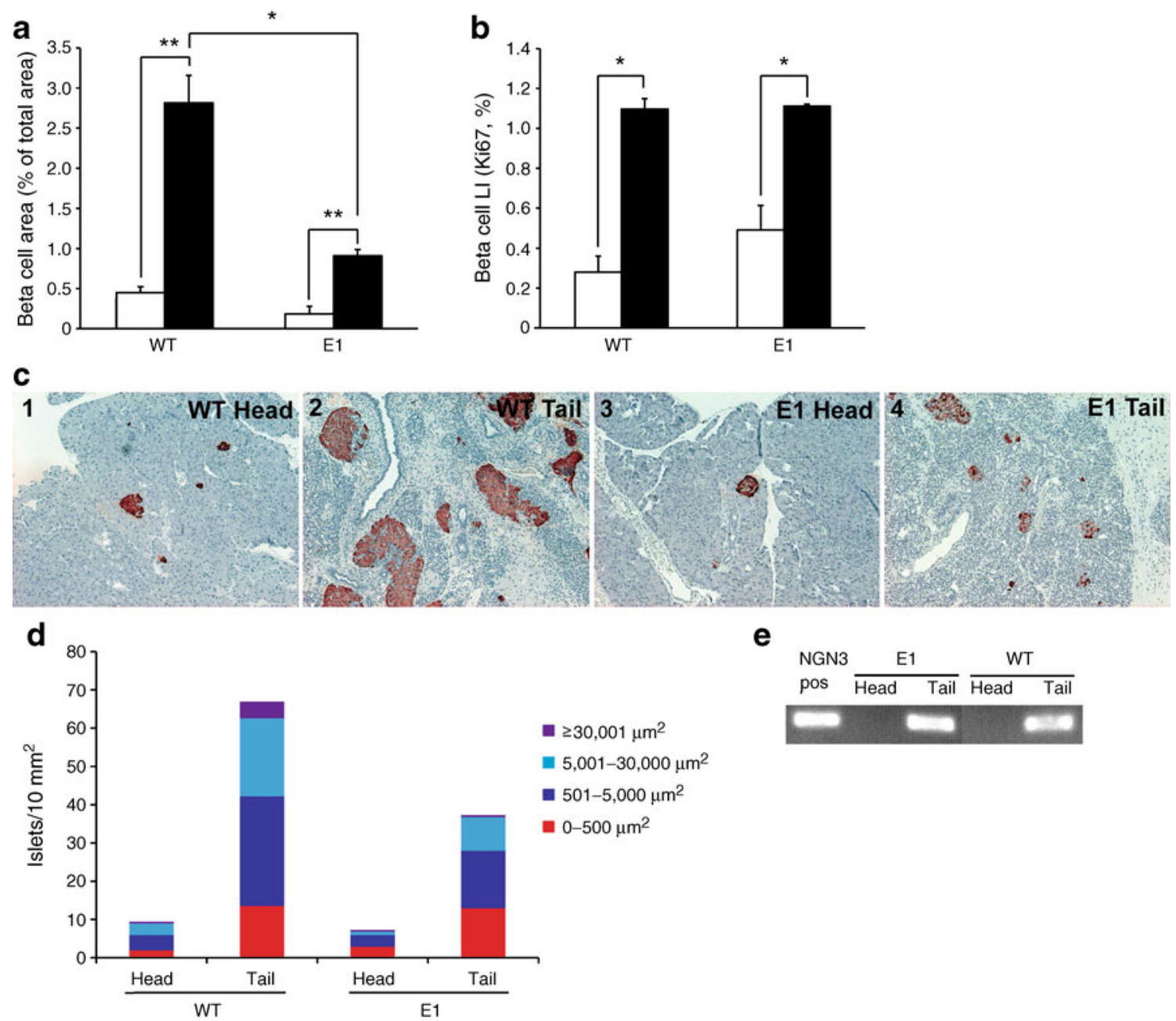

e

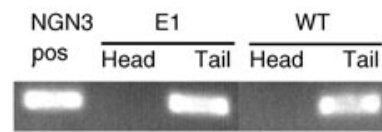

morphological changes in the tail part of the ligated pancreas. Original magnification $\times 4$. d The islet number and islet size distribution per $10 \mathrm{~mm}^{2}$ in head and tail parts of the ligated pancreas. Red, 0-500 $\mathrm{\mu m}^{2}$; dark blue, 501-5,000 $\mathrm{\mu m}^{2}$; light blue, 5,001$30,000 \mu \mathrm{m}^{2}$; purple, $\geq 31,000 \mu \mathrm{m}^{2}$ e $N g n 3$ expression was detected in the ligated tail part of the pancreas in both the wild-type and E1-DN but not in the unligated head part of the pancreas in RT-PCR. Values represent mean \pm SE. ${ }^{*} p<0.05,{ }^{* *} p<0.01$. pos, positive; WT, wild type

(Fig. 3d). In the wild-type mice this was due to an increase in all sizes of islets, whereas in the E1-DN mice the increase was more prominent in the small- and mediumsized islets $\left(\leq 30,000 \mu \mathrm{m}^{2}\right)$ and was not significant in the large islets $\left(\geq 30,001 \mu \mathrm{m}^{2}\right)$ (Fig. 3d). The proportion of large islets $\left(\geq 30,001 \mu \mathrm{m}^{2}\right)$ after the operation was $6.5 \%$ in the wild-type mice and only $1.3 \%$ in the E1-DN. However, the proportion of large islets was low even in the head part of the E1 mice $(0.3 \%)$, suggesting that the difference in islet size distribution was not due to the pancreatic duct ligation but the inherent phenotype of the E1-DN mice (Fig. 3d).

Insulin and glucagon double staining revealed some cells double positive for insulin and glucagon in the ligated tail part of both wild-type and E1-DN mice. These cells were not found in the non-ligated pancreases (Fig. $4 \mathrm{a}-\mathrm{d}$ ). In the E1-DN mice these double-positive cells were also positive for human EGFR (hEGFR), an indication of transgene expression (Fig. 4e-f).

\section{Discussion}

EGFR ligands such as epidermal growth factor (EGF), heparin-binding EGF and betacellulin have been implicated in both beta cell replication and differentiation [29, 32-34]. 

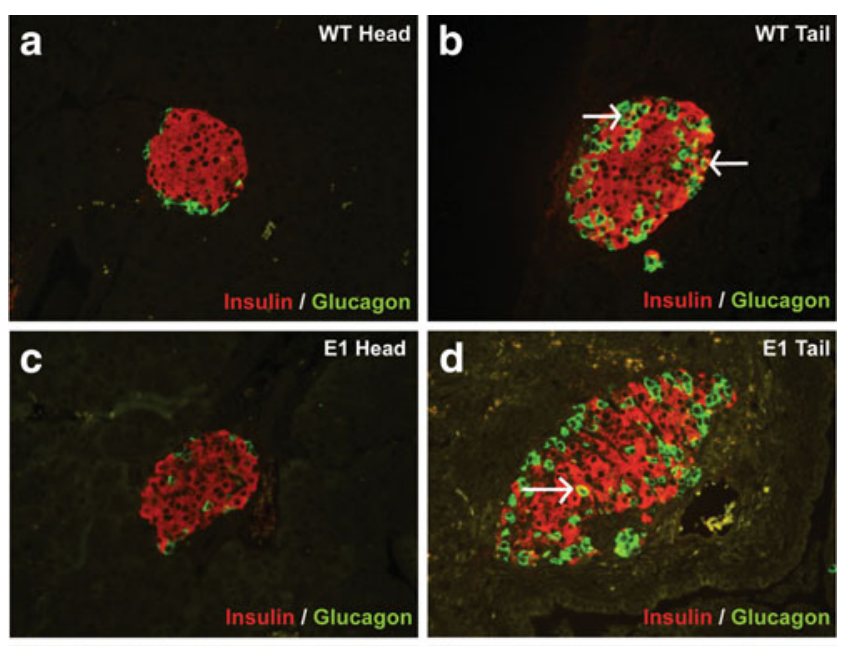

\section{e}
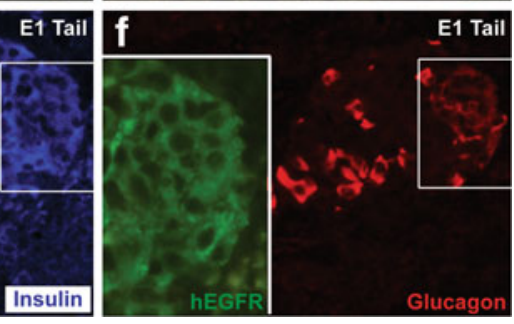

Fig. 4 Insulin and glucagon double-immunoreactive cells were present in the ligated tail part of pancreas after pancreatic duct ligation. a-d Insulin (red) and glucagon (green) double-positive cells, detected by yellow fluorescence, were present in the pancreatic tail of both (b) wild-type and (d) E1-DN mice, indicated with white arrows. These cells were not present in the unligated pancreatic head in (a) wild-type or (c) E1-DN mice. e,f In the E1-DN tail pancreas, the insulin (e, blue) and glucagon (f, red) double-immunoreactive cells (e, higher magnification, seen in purple) were also positive for the E1-DN transgene, stained with anti-hEGFR (f, higher magnification, green). Representative islets are shown (original magnification: $\mathbf{a}-\mathbf{d} \times 20 ; \mathbf{e}, \mathbf{f} \times 40$ )

In addition to direct ligand-induced activation of EGFR, transactivation of the receptor is also associated with other mitogenic receptor signalling pathways, including the glucagon-like peptide 1 (GLP-1) receptor pathway [35]. In this study we wanted to explore the importance of EGFR signalling in vivo in beta cell mass expansion in adults. We specifically chose models in which the beta cell mass expansion is known to primarily involve replication (highfat diet and pregnancy) and a model where neogenesis is crucial for the generation of new beta cells (pancreatic duct ligation). The E1-DN mice, which produce a kinasenegative and non-functional EGFR in beta cells under the $P d x 1$ promoter, were used to evaluate the contribution of EGFR signalling. In this model the phosphorylation of EGFR and the activation of downstream-signalling molecules in beta cells is reduced by approximately $40 \%$ in homozygous animals [31]. The phenotype of heterozygous E1-DN mice, which were used in these experiments, is less pronounced, and the heterozygous mice are nearly normo- glycaemic under normal circumstances. However, when metabolically challenged these mice showed impaired beta cell compensation.

Our results confirm that EGFR plays a pivotal role in beta cell proliferation, as the beta cells of the E1-DN mice failed to replicate during pregnancy. Also, during high-fat feeding, the wild-type mice showed a compensatory increase in their beta cell mass that was lacking in the transgenic mice. Surprisingly, we did not detect a significant increase in beta cell proliferation even in the wild-type mice during high-fat feeding, although there was a trend for this effect (Fig. 1e-f). Analysis of beta cell size, apoptosis or neogenesis did not provide any explanation for the changing beta cell mass. Based on previous studies, the most probable explanation for the increase in beta cell mass while on the high-fat diet is beta cell replication. Most likely, the actual difference in the rate of replication was relatively small, and we failed to study it at the optimal time.

The basal beta cell replication rate of the adult heterozygous E1-DN mice was not different from wildtype mice in males or females. However, when the mice were metabolically challenged, the E1-DN mice completely failed to increase their rate of beta cell proliferation. In our previous study we showed that postnatal beta cell proliferation is attenuated in homozygous E1-DN mice [31]. In this study even the heterozygous mice failed to increase beta cell proliferation when metabolically challenged by high-fat diet or pregnancy. Inability to compensate for the increased metabolic demand in the E1-DN mice led to an insufficient beta cell mass and impaired glucose tolerance.

Multiple intracellular signalling pathways participate in beta cell proliferation. These pathways include protein kinase A pathways, mitogen-activated protein kinase (MAPK) pathways, janus kinase (JAK)-signal transducer and activator of transcription (STAT) pathways, phosphatidyl inositol-3 (PI3) kinase/protein kinase B (AKT) pathways and insulin-receptor-substrate pathways [36]. These signalling cascades lead to $\mathrm{G}_{1} / \mathrm{S}$ transition, mainly by stimulating the activity of the cyclin-dependent-kinase 4-cyclin D complex [8, 37-39]. The EGFR has been shown to activate the RAS- and SHC-activated MAPK pathway and the PI3 kinase-activated AKT pathway [40]. It has also been shown to have a role in GLP-1 downstream signalling, as part of the mitogenic effect of GLP-1 appears to act through the EGFR [35, 41]. Recently it has been shown that EGFR regulates the stability of survivin [42], an oncofetal protein with both pro-proliferative and antiapoptotic functions. Furthermore, it was also shown that, during pregnancy, the synthesis of serotonin and its receptor 5-hydroxytryptamine receptor-2b (5-HTR2B) are upregulated in beta cells and by inhibiting the $5-\mathrm{Htr} 2 \mathrm{~b}$, the maternal beta cell mass expansion is blocked [43, 44]. 
Interesting in this context is the evidence that 5-HTR2B transactivates the EGFR in astrocytes [45]. It is thus possible that EGFR is transactivated through 5-HTR2B during pregnancy and this is needed for beta cell mitogenesis. This could explain the failure of beta cell proliferation in pregnant E1-DN mice. Several lines of evidence suggest that EGFR could have a central position at the crossroads of signalling pathways that are crucial for the triggering of the cell cycle in the beta cell. Further studies are needed to verify some of these links, such as that between serotonin and EGFR signalling in pregnancy.

Pancreatic regeneration following pancreatic duct ligation involves both islet neogenesis and islet cell proliferation. Neogenesis after pancreatic duct ligation has been convincingly demonstrated to be based on the reactivation of embryonic differentiation programs [23]. As a sign of this we detected Ngn 3 expression in the ligated pancreases of both wild-type and transgenic mice. The relative growth of the beta cell surface area was equal in the E1-DN and the wild-type mice. Interestingly, the rate of beta cell proliferation increased to a similar level in E1-DN mice and wildtype mice. As beta cell proliferation was markedly reduced in E1-DN mice in the other two models studied, this suggests that the mechanisms of beta cell proliferation are fundamentally different in the pancreatic duct ligation model from those in the more physiological models of insulin resistance. Ligation of the pancreatic duct leads to acute strong inflammation [46], which induces rapid beta cell mass expansion within days. Based on these results it appears that the 'cytokine storm' in the inflamed ligated pancreas is able to induce the regenerative response without an intact EGFR-signalling pathway.

The origin of neogenic beta cells in the pancreatic duct ligation model is still controversial after several lineage tracing studies [47, 48]. Labelling based on $\operatorname{Hnfl} \beta$ (also known as Hnflb) promoter activity suggests that these cells do not originate from ductal cells [48]. However, another lineage-tracing study based on the human carbonic anhydrase II promoter, which targets reporter expression in the ductal epithelial cells, suggested that a significant part of the regenerated beta cells had arisen from the duct epithelium [49]. One possibility is that the new beta cells arise from transdifferentiating alpha cells, as has been shown to be the case after a combination of pancreatic duct ligation and elimination of pre-existing beta cells with alloxan [50]. We specifically looked for insulin and glucagon co-localisation in the ligated and non-ligated parts of the pancreas and found some double-positive cells in the tail part of the ligated pancreases. These cells were also positive for hEGFR, showing that they have activated $P d x I$ promoter, which drives the transgene expression (Fig. 4). However, we are not able to conclude whether these cells represent alpha to beta cell conversion. Definitive proof of this will require genetic lineage tracing analysis. Nevertheless, our results suggest that EGFR signalling does not play a primary role in beta cell proliferation after pancreatic duct ligation.

In summary, our study elucidates the specific role of growth factors that act through EGFR to regulate the beta cell mass. The results provide further confirmation of the essential role of the EGFR in the signalling cascade leading to cell cycle progression in the beta cell. Furthermore, we also show that beta cell expansion following pancreatic duct ligation is not dependent on this signalling pathway.

Acknowledgements We thank N. De Medts for her help with the pancreatic duct ligation experiment and P. Ormio for her help in the beginning of these experiments. U. Kiiski and E. Hurskainen are thanked for technical assistance. These studies were funded by European Union (STREP SAVEBETA, contract no. 036903) in the 6th Framework Program, the Diabetes Research Foundation, a research grant from Helsinki University Central Hospital, the Foundation for Pediatric Research and Sigrid Juselius Foundation.

Duality of interest statement The authors declare that there is no duality of interest associated with this manuscript.

\section{References}

1. Bouwens L, Rooman I (2005) Regulation of pancreatic beta-cell mass. Physiol Rev 85:1255-1270

2. Finegood DT, Scaglia L, Bonner-Weir S (1995) Dynamics of betacell mass in the growing rat pancreas. Estimation with a simple mathematical model. Diabetes 44:249-256

3. Dor Y, Brown J, Martinez OI, Melton DA (2004) Adult pancreatic beta-cells are formed by self-duplication rather than stem-cell differentiation. Nature 429:41-46

4. Teta M, Long SY, Wartschow LM, Rankin MM, Kushner JA (2005) Very slow turnover of beta-cells in aged adult mice. Diabetes 54:2557-2567

5. Pick A, Clark J, Kubstrup C et al (1998) Role of apoptosis in failure of beta-cell mass compensation for insulin resistance and beta-cell defects in the male Zucker diabetic fatty rat. Diabetes 47:358-364

6. Sorenson RL, Brelje TC (1997) Adaptation of islets of Langerhans to pregnancy: beta-cell growth, enhanced insulin secretion and the role of lactogenic hormones. Horm Metab Res 29:301-307

7. Parsons JA, Brelje TC, Sorenson RL (1992) Adaptation of islets of Langerhans to pregnancy: increased islet cell proliferation and insulin secretion correlates with the onset of placental lactogen secretion. Endocrinology 130:1459-1466

8. Georgia S, Hinault C, Kawamori D et al (2010) Cyclin D2 is essential for the compensatory beta-cell hyperplastic response to insulin resistance in rodents. Diabetes 59:987-996

9. Terauchi Y, Takamoto I, Kubota N et al (2007) Glucokinase and IRS2 are required for compensatory beta cell hyperplasia in response to high-fat diet-induced insulin resistance. J Clin Invest 117:246-257

10. Bruning JC, Winnay J, Bonner-Weir S, Taylor SI, Accili D, Kahn CR (1997) Development of a novel polygenic model of NIDDM in mice heterozygous for IR and IRS-1 null alleles. Cell 88:561-572

11. Jetton TL, Lausier J, LaRock K et al (2005) Mechanisms of compensatory beta-cell growth in insulin-resistant rats: roles of Akt kinase. Diabetes 54:2294-2304

12. Sachdeva MM, Stoffers DA (2009) Minireview: Meeting the demand for insulin: molecular mechanisms of adaptive postnatal beta-cell mass expansion. Mol Endocrinol 23:747-758 
13. Butler AE, Janson J, Bonner-Weir S, Ritzel R, Rizza RA, Butler PC (2003) Beta-cell deficit and increased beta-cell apoptosis in humans with type 2 diabetes. Diabetes 52:102-110

14. Karnik SK, Chen H, McLean GW et al (2007) Menin controls growth of pancreatic beta-cells in pregnant mice and promotes gestational diabetes mellitus. Science 318:806-809

15. Butler AE, Cao-Minh L, Galasso R et al (2010) Adaptive changes in pancreatic beta cell fractional area and beta cell turnover in human pregnancy. Diabetologia 53:2167-2176

16. Teta M, Rankin MM, Long SY, Stein GM, Kushner JA (2007) Growth and regeneration of adult beta cells does not involve specialized progenitors. Dev Cell 12:817-826

17. Georgia S, Bhushan A (2004) Beta cell replication is the primary mechanism for maintaining postnatal beta cell mass. J Clin Invest 114:963-968

18. Alonso LC, Yokoe T, Zhang P et al (2007) Glucose infusion in mice: a new model to induce beta-cell replication. Diabetes 56:1792-1801

19. Wang RN, Kloppel G, Bouwens L (1995) Duct- to islet-cell differentiation and islet growth in the pancreas of duct-ligated adult rats. Diabetologia 38:1405-1411

20. Bonner-Weir S, Li WC, Ouziel-Yahalom L, Guo L, Weir GC, Sharma A (2010) Beta-cell growth and regeneration: replication is only part of the story. Diabetes 59:2340-2348

21. Li WC, Rukstalis JM, Nishimura W et al (2010) Activation of pancreatic-duct-derived progenitor cells during pancreas regeneration in adult rats. J Cell Sci 123:2792-2802

22. Bonner-Weir S, Baxter LA, Schuppin GT, Smith FE (1993) A second pathway for regeneration of adult exocrine and endocrine pancreas. A possible recapitulation of embryonic development. Diabetes 42:1715-1720

23. Xu X, D'Hoker J, Stange G et al (2008) Beta cells can be generated from endogenous progenitors in injured adult mouse pancreas. Cell 132:197-207

24. Thorel F, Nepote V, Avril I et al (2010) Conversion of adult pancreatic alpha-cells to beta-cells after extreme beta-cell loss. Nature 464:1149-1154

25. Schlessinger J, Ullrich A (1992) Growth factor signaling by receptor tyrosine kinases. Neuron 9:383-391

26. Kraus MH, Issing W, Miki T, Popescu NC, Aaronson SA (1989) Isolation and characterization of ERBB3, a third member of the ERBB/epidermal growth factor receptor family: evidence for overexpression in a subset of human mammary tumors. Proc Natl Acad Sci USA 86:9193-9197

27. Plowman GD, Culouscou JM, Whitney GS et al (1993) Ligandspecific activation of HER4/p180erbB4, a fourth member of the epidermal growth factor receptor family. Proc Natl Acad Sci USA 90:1746-1750

28. Kritzik MR, Krahl T, Good A et al (2000) Expression of ErbB receptors during pancreatic islet development and regrowth. J Endocrinol 165:67-77

29. Huotari MA, Miettinen PJ, Palgi J et al (2002) ErbB signaling regulates lineage determination of developing pancreatic islet cells in embryonic organ culture. Endocrinology 143:4437-4446

30. Miettinen PJ, Huotari M, Koivisto $T$ et al (2000) Impaired migration and delayed differentiation of pancreatic islet cells in mice lacking EGF-receptors. Development 127:2617-2627

31. Miettinen PJ, Ustinov J, Ormio P et al (2006) Downregulation of EGF receptor signaling in pancreatic islets causes diabetes due to impaired postnatal beta-cell growth. Diabetes 55:3299-3308
32. Vinter-Jensen L, Juhl CO, Teglbjaerg PS, Poulsen SS, Dajani EZ, Nexo E (1997) Systemic treatment with epidermal growth factor in pigs induces ductal proliferations in the pancreas. Gastroenterology 113:1367-1374

33. Cras-Meneur C, Elghazi L, Czernichow P, Scharfmann R (2001) Epidermal growth factor increases undifferentiated pancreatic embryonic cells in vitro: a balance between proliferation and differentiation. Diabetes 50:1571-1579

34. Means AL, Ray KC, Singh AB et al (2003) Overexpression of heparin-binding EGF-like growth factor in mouse pancreas results in fibrosis and epithelial metaplasia. Gastroenterology 124:1020-1036

35. Buteau J, Foisy S, Joly E, Prentki M (2003) Glucagon-like peptide 1 induces pancreatic beta-cell proliferation via transactivation of the epidermal growth factor receptor. Diabetes 52:124-132

36. Cozar-Castellano I, Fiaschi-Taesch N, Bigatel TA et al (2006) Molecular control of cell cycle progression in the pancreatic beta-cell. Endocr Rev 27:356-370

37. Brennand K, Melton D (2009) Slow and steady is the key to beta-cell replication. J Cell Mol Med 13:472-487

38. Rane SG, Dubus P, Mettus RV et al (1999) Loss of Cdk4 expression causes insulin-deficient diabetes and $\mathrm{Cdk} 4$ activation results in beta-islet cell hyperplasia. Nat Genet 22:44-52

39. Cozar-Castellano I, Harb G, Selk K et al (2008) Lessons from the first comprehensive molecular characterization of cell cycle control in rodent insulinoma cell lines. Diabetes 57:3056-3068

40. Yarden Y (2001) The EGFR family and its ligands in human cancer. signalling mechanisms and therapeutic opportunities. Eur J Cancer 37(Suppl 4):S3-8

41. MacDonald PE, Wang X, Xia F et al (2003) Antagonism of rat betacell voltage-dependent $\mathrm{K}+$ currents by exendin 4 requires dual activation of the cAMP/protein kinase A and phosphatidylinositol 3kinase signaling pathways. J Biol Chem 278:52446-52453

42. Wang H, Gambosova K, Cooper ZA et al (2010) EGF regulates survivin stability through the Raf-1/ERK pathway in insulinsecreting pancreatic beta-cells. BMC Mol Biol 11:66

43. Schraenen A, Lemaire K, de Faudeur G et al (2010) Placental lactogens induce serotonin biosynthesis in a subset of mouse beta cells during pregnancy. Diabetologia 53:2589-2599

44. Kim H, Toyofuku Y, Lynn FC et al (2010) Serotonin regulates pancreatic beta cell mass during pregnancy. Nat Med 16:804-808

45. Li B, Zhang S, Zhang H et al (2008) Fluoxetine-mediated 5-HT2B receptor stimulation in astrocytes causes EGF receptor transactivation and ERK phosphorylation. Psychopharmacol Berl 201:443-458

46. Meyerholz DK, Williard DE, Grittmann AM, Samuel I (2008) Murine pancreatic duct ligation induces stress kinase activation, acute pancreatitis, and acute lung injury. Am J Surg 196:675-682

47. Bonner-Weir S, Inada A, Yatoh S et al (2008) Transdifferentiation of pancreatic ductal cells to endocrine beta-cells. Biochem Soc Trans 36:353-356

48. Solar M, Cardalda C, Houbracken I et al (2009) Pancreatic exocrine duct cells give rise to insulin-producing beta cells during embryogenesis but not after birth. Dev Cell 17:849-860

49. Inada A, Nienaber C, Katsuta $H$ et al (2008) Carbonic anhydrase II-positive pancreatic cells are progenitors for both endocrine and exocrine pancreas after birth. Proc Natl Acad Sci USA 105:19915-19919

50. Chung CH, Hao E, Piran R, Keinan E, Levine F (2010) Pancreatic beta-cell neogenesis by direct conversion from mature alpha-cells. Stem Cells 28:1630-1638 